\title{
Prevalence, etiology, and biopsychosocial risk factors of cervicogenic dizziness in patients with neck pain: A multi-center, cross-sectional study
}

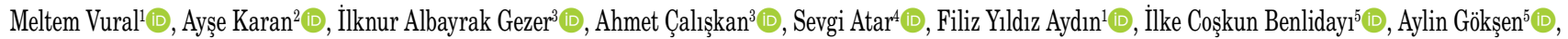

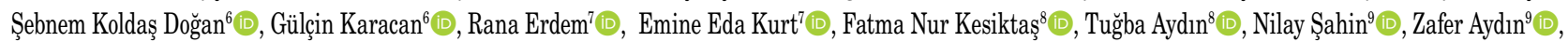

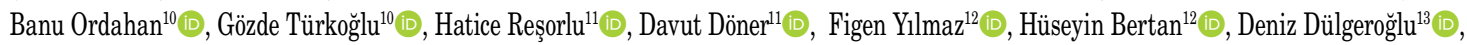

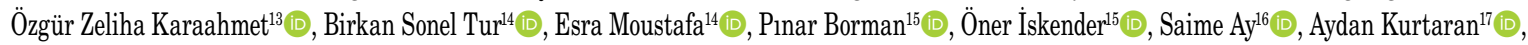

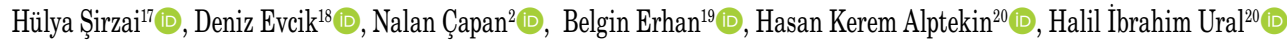

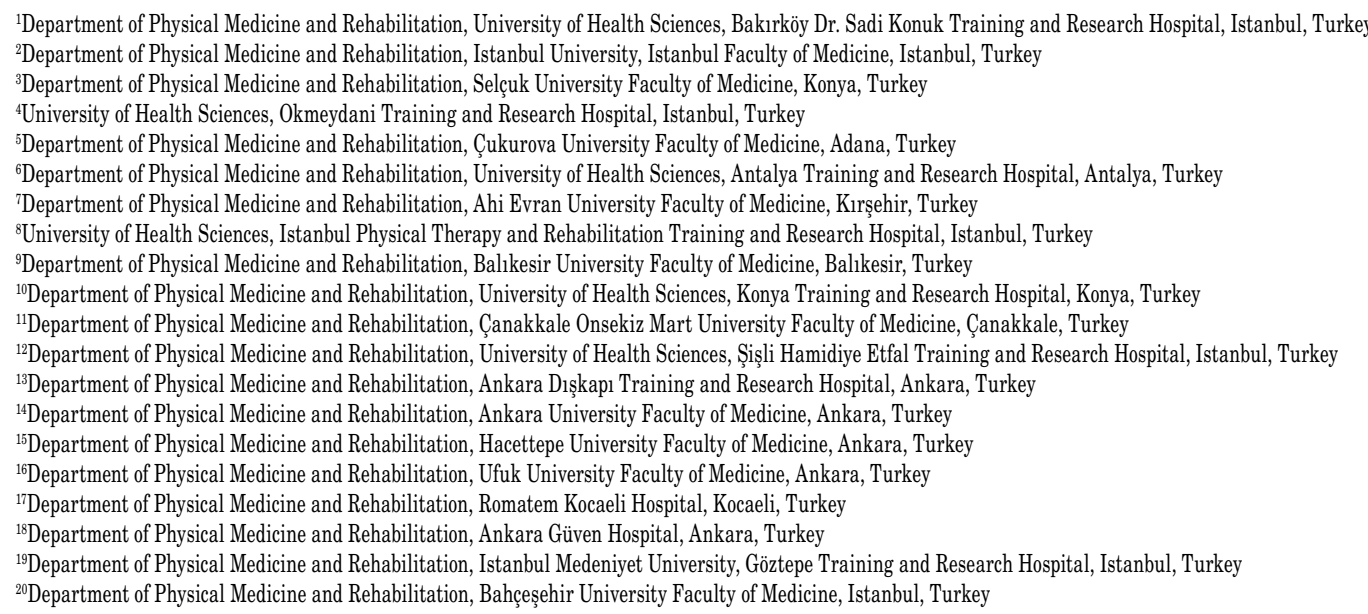

Received: December 18, 2020 Accepted: February 03, 2021 Published online: December 01, 2021

\begin{abstract}
Objectives: This study aims to investigate the prevalence, etiology, and risk factors of cervicogenic dizziness in patients with neck pain.

Patients and methods: Between June 2016 and April 2018, a total of 2,361 patients (526 males, 1,835 females; mean age: $45.0 \pm 13.3$ years; range, 18 to 75 years) who presented with the complaint of neck pain lasting for at least one month were included in this prospective, cross-sectional study. Data including concomitant dizziness, severity, and quality of life (QoL) impact of vertigo (via Numeric Dizziness Scale [NDS]), QoL (via Dizziness Handicap Inventory [DHI]), mobility (via Timed Up-and-Go [TUG] test), balance performance [via Berg Balance Scale [BBS]), and emotional status (via Hospital AnxietyDepression Scale [HADS]) were recorded.

Results: Dizziness was evident in $40.1 \%$ of the patients. Myofascial pain syndrome (MPS) was the most common etiology for neck pain (58.5\%) and accompanied with cervicogenic dizziness in $59.7 \%$ of the patients. Female versus male sex (odds ratio [OR]: 1.641, 95\% CI: 1.241 to 2.171 , p $=0.001$ ), housewifery versus other occupations (OR: $1.285,95 \%$ CI: 1.006 to $1.642, p=0.045)$, and lower versus higher education (OR: $1.649-2.564, p<0.001)$ significantly predicted the increased risk of dizziness in neck pain patients. Patient with dizziness due to MPS had lower dizziness severity scores ( $\mathrm{p}=0.034)$ and milder impact of dizziness on QoL $(\mathrm{p}=0.005)$, lower DHI scores $(\mathrm{p}=0.004)$, shorter time to complete the TUG test $(\mathrm{p}=0.001)$ and higher BBS scores $(\mathrm{p}=0.001)$.

Conclusion: Our findings suggest a significant impact of biopsychosocial factors on the likelihood and severity of dizziness and association of dizziness due to MPS with better clinical status.
\end{abstract}

Keywords: Balance, cervicogenic dizziness, handicap, myofascial pain syndrome, neck pain.

Corresponding author: Meltem Vural, MD. Bakırköy Dr. Sadi Konuk Eğitim ve Araştırma Hastanesi Fiziksel Tıp ve Rehabilitasyon Kliniği, 34147 Bakırköy, İstanbul, Türkiye. e-mail: drmeltemvural@gmail.com

Cite this article as:

Vural M, Karan A, Albayrak Gezer İ, Çalışkan A, Atar S, Ylldız Aydın F et al. Prevalence, etiology, and biopsychosocial risk factors of cervicogenic dizziness in patients with neck pain: A multi-center, cross-sectional study. Turk J Phys Med Rehab 2021;67(x):399-408.

Presented at the $26^{\text {h }}$ Congress of the National Congress of Physical Medicine and Rehabilitation, April 25-29, 2017 in Antalya, Turkey 
Neck pain and dizziness (including vertigo and non-vestibular dizziness) rank among the most common complaints in medical practice. ${ }^{[1-3]}$ The simultaneous presence of neck pain and cervicogenic dizziness is frequent and considered to occur via a causal rather than a coincidental relationship. ${ }^{[4,5]}$

Cervicogenic dizziness refers to a non-specific sensation of altered orientation in space and disequilibrium causing erroneous proprioceptive information and a sensory mismatch between vestibular and cervical inputs. ${ }^{[2,4,6-9]}$ However, among the various causes of dizziness, cervicogenic dizziness has long been a controversial entity with no consensus regarding its pathophysiology, diagnostic criteria, and optimal treatment. ${ }^{[2,8,10,11]}$ There is no diagnostic method or specific test to link the patient's dizziness to underlying neck condition. ${ }^{[10-12]}$

In the literature, there is only a limited number of data about the prevalence of cervicogenic dizziness, while the diagnosis is usually based on exclusion of vestibular disorders and presence of correlating symptoms of imbalance and dizziness with neck pain. ${ }^{[2,6,9,10,13]}$ In the present study, we aimed to determine prevalence and etiology of cervicogenic dizziness and to identify potential sociodemographic, clinical, and psychological risk factors for vertigo in patients with neck pain.

\section{PATIENTS AND METHODS}

\section{Study design and study population}

This multi-center, prospective, cross-sectional study was conducted at Physical Medicine \& Rehabilitation (PMR) clinics across Turkey between June 2016 and April 2018. A total of 2,361 patients (526 males, 1,835 females; mean age: $45.0 \pm 13.3$ years; range, 18 to 75 years) who presented with the complaint of neck pain lasting for at least one month were included. Age between 18 and 75 years, literacy and having neck pain for at least one month were the inclusion criteria of the study, while patients with psychiatric, neurological, cardiac (medical history or electocardiographic abnormality) or rheumatological disorder, congenital anomalies of cervical region, vestibular pathologies with neck pain and stiffness (i.e., labyrinthine concussion, vestibular migraines), other etiologies accompanying myofascial pain syndrome (MPS), previous craniocervical surgery, organic pathology of the vertebrobasilar system, concomitant middle ear pathology or medication usage associated with risk of dizziness, mass lesions in brain or spinal medulla, malignancy, pregnancy, and dizziness episodes accompanied with extensive vomiting were excluded from the study. A written informed consent was obtained from each patient. The study protocol was approved by the Ethics Committee of Bakırköy Dr. Sadi Konuk Training Hospital, (No: 2016/03/04, Date: 11.04.2016). The study was conducted in accordance with the principles of the Declaration of Helsinki.

\section{Data collection}

Data including sociodemographic characteristics, etiology and duration of neck pain, presence of concomitant dizziness were recorded. A detailed physical examination including locomotor system and neurological examination, presence of trigger points associated with MPS-related vertigo (i.e., sternocleidomastoid and trapezius muscles), as well as check of range of motion across cervical vertebrae through neck assessment was performed. Previous imaging findings on cervical spine $\mathrm{X}$-ray and cervical magnetic resonance imaging were reviewed for conditions such as spondylosis or disc herniation. Biopsychosocial assessment regarding the severity and quality of life (QoL) impact of vertigo (via Numeric Dizziness Scale [NDS]), QoL (via Dizziness Handicap Inventory [DHI]), mobility (via Timed Up-and-Go [TUG] test), balance performance [via Berg Balance Scale [BBS]), and emotional status (via Hospital Anxiety-Depression Scale [HADS]) was performed by PMR specialists experienced in vestibular rehabilitation. Baseline characteristics, clinical, and biopsychosocial findings were evaluated according to presence, etiology and severity of dizziness, while risk factors for dizziness presence in patients with neck pain were also analyzed.

\section{Numeric Dizziness Scale}

The severity of vertigo and the impact of vertigo on QoL were assessed by a 10-point NDS with higher scores indicating higher severity of vertigo and marked impact on QoL.

\section{Timed Up-and-Go test}

The 3-m TUG test was used as a performance-based test of the functional mobility and the risk of falling. The participant is asked to rise from a seated position in a chair and walk a distance of $3 \mathrm{~m}$, turn around and return to a sitting position as quickly and safely as possible. Time is recorded by the nearest time of the person's buttocks leave the chair until return contact with the chair. The shorter time indicates better physical performance, while the test is considered to have good predictive ability and diagnostic accuracy in discriminating fallers from non-fallers. ${ }^{[14,15]}$ 


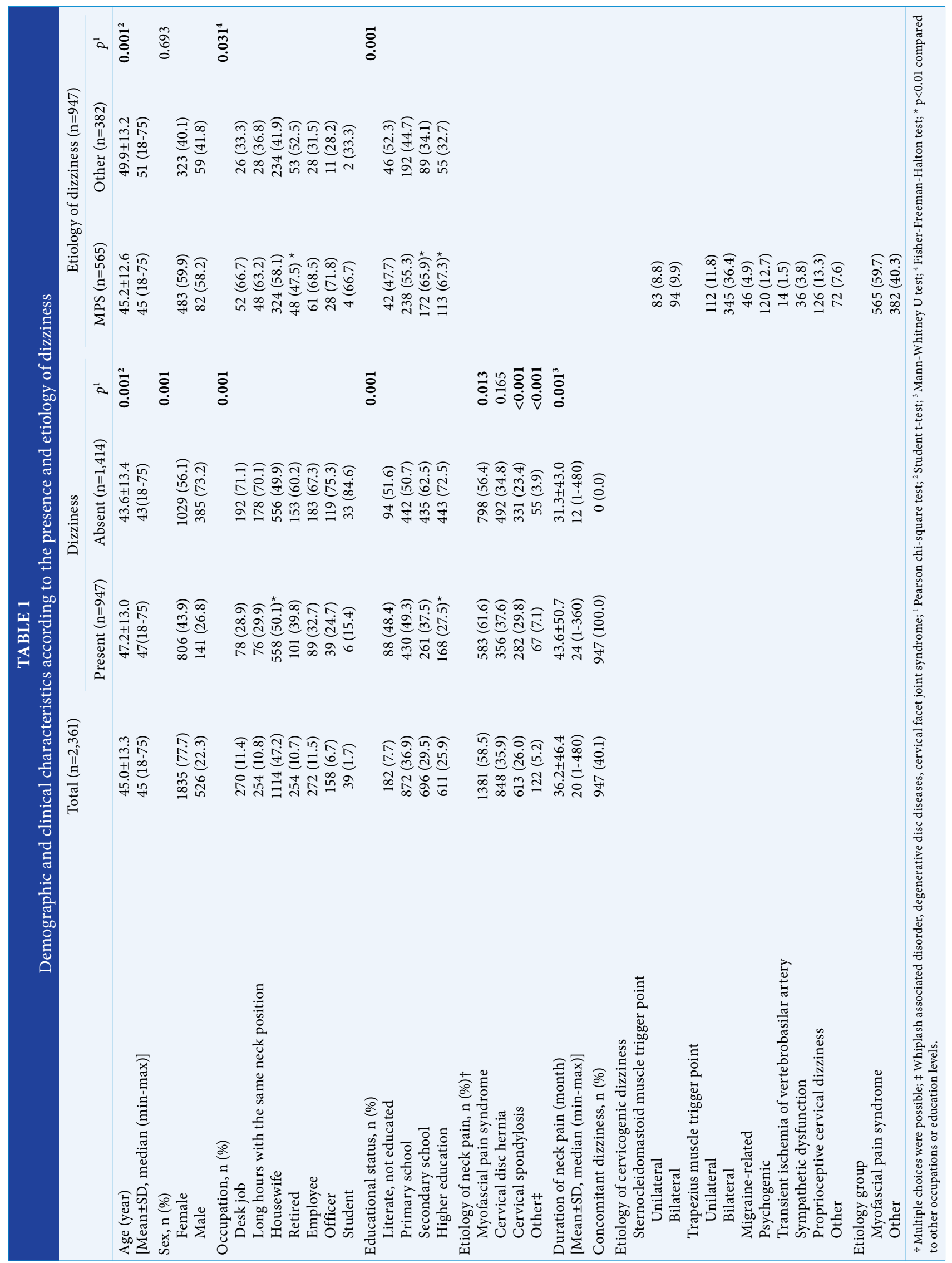




\section{Dizziness Handicap Inventory}

The DHI, developed by Jacobson and Newman, ${ }^{[16]}$ is a 25 -item instrument used for self-assessment of disability due to dizziness. It consists of three sub-domains including functional (9 items), physical ( 7 items), and emotional (9 items) domains. Each item is scored based on a 1-3 Likert scale (0: no, 2: sometimes, 4 : yes) that yields the functional, physical and emotional domain scores in a range of $0-36,0-28$ and 0-36, respectively and a total score of 0-100. Higher scores indicate a greater degree of impairment. ${ }^{[16,17]}$ The reliability and validity of Turkish version of DHI were conducted by Ellialtioglu et al. ${ }^{[18]}$

\section{Berg Balance Scale}

The BBS is a 14-item tool designed by Berg et al. ${ }^{[19]}$ and Berg et al. ${ }^{[20]}$ to measure functional balance. The total score of BBS ranges from 0 to 56 , and greater scores indicate better balance. The results are categorized as balance disorder (scores 0-20), acceptable balance (scores 21-40) and good balance (scores 41-56). ${ }^{[19,20]}$ The reliability and validity of Turkish version of DHI were conducted by Sahin et al. ${ }^{[21]}$

\section{Hospital Anxiety and Depression Scale}

The HADS, developed by Zigmond and Snaith, ${ }^{[22]}$ is a 14 -item (seven related to anxiety [HADS-A] and seven related to depression [HADS-D]) scale used to screen anxiety and depression in medical outpatient settings. ${ }^{[2,23]}$ Each item on the questionnaire is scored from 0-3 leading overall score to range between 0 and 21 for either anxiety or depression as categorized into normal (scores 0-7), borderline abnormal (scores 8-10) and abnormal (scores 11-21) status. ${ }^{[22,23]}$ The HADS was adapted to Turkish by Aydemir ${ }^{[24]}$ with cut-off points of 10 and 7 defined for HADS-A and HADS-D subscales, respectively.

\section{Statistical analysis}

Statistical analysis was performed using the NCSS version 2007 software (NCSS LLC, Kaysville, UT, USA). Descriptive data were expressed in mean \pm standard deviation (SD), median (min-max) or number and frequency, where applicable. The Pearson chi-square $\left(\chi^{2}\right)$ test, Fisher-Freeman-Halton test and Fisher exact test were used to compare categorical data, while numerical data were analyzed using the Student t-test for variables with normal distribution and with Mann-Whitney $\mathrm{U}$ and Kruskal Wallis tests for non-normally distributed variables. Backward stepwise logistic regression analysis was performed to identify factors associated with the increased risk for dizziness in patients with neck pain. Correlation analysis was performed using the Pearson correlation analysis. A $p$ value of $<0.05$ was considered statistically significant with $95 \%$ confidence interval (CI).

\section{RESULTS}

\section{Demographic and clinical characteristics}

The majority of the participants were housewives, while $36.9 \%$ of participants were primary school graduates. Neck pain was due to MPS in $58.5 \%$ of patients. Concomitant dizziness was evident in 947 (40.1\%) patients (Table 1). The presence of dizziness was associated with the increasing age $(47.2 \pm 13.0$ vs. $43.6 \pm 13.4$, respectively; $\mathrm{p}=0.001)$, a higher rate of females ( 43.9 vs. $26.8 \%$, respectively; $\mathrm{p}=0.001$ ), a higher likelihood of housewifery than other occupations $(\mathrm{p}=0.001)$, a lower rate of higher education (27.5 vs. $72.5 \%$, respectively; $\mathrm{p}<0.01$ ), longer duration of neck pain $(43.6 \pm 50.7$ vs. $31.3 \pm 43.0$ months, respectively; $\mathrm{p}=0.001)$ and a higher likelihood of MPS (61.6 vs. $56.4 \%$, respectively; $\mathrm{p}=0.013$ ) in the etiology of neck pain (Table 1).

Overall, cervicogenic dizziness was accompanied with MPS in $59.7 \%$ of the patients. In patients with dizziness $(n=947)$, those with dizziness due to MPS versus other reasons aged younger $(45.2 \pm 12.6 \mathrm{vs}$. $49.9 \pm 13.2$ years, respectively; $\mathrm{p}=0.001)$, had a lower rate of retirement (47.5 vs. 52.5\%, respectively; $\mathrm{p}=0.031$ ) and a higher rate of secondary $(65.9$ vs. $34.1 \%$, respectively; $\mathrm{p}=0.001)$ or higher education (67.3 vs. $32.7 \%$, respectively; $\mathrm{p}=0.001$ ) (Table 1 ).

\section{Biopsychological findings}

Presence versus absence of dizziness was associated with a higher likelihood of presence of sternocleidomastoid muscle trigger point (44.4 vs. $24.6 \%$, respectively; $\mathrm{p}=0.001$ ), longer time to complete the TUG test (11.1 \pm 4.7 ; range, 3 to $92 v s .7 .7 \pm 3.8$; range, 3 to $25 \mathrm{sec}$, respectively; $\mathrm{p}=0.001$ ), lower BBS scores (poorer balance; 51.1 \pm 6.0 vs. 55.6 \pm 1.5 , respectively; $\mathrm{p}=0.001)$ and higher HADS-D scores (8.6 $\pm 6.1 v s$. $6.8 \pm 5.8$, respectively; $\mathrm{p}=0.002$ ) (Table 2 ).

In patients with dizziness ( $\mathrm{n}=947)$, those with dizziness due to MPS versus other reasons had lower DHI scores (lesser impairment; $33.7 \pm 20.2$ vs. $37.6 \pm 20.8$, respectively; $\mathrm{p}=0.004)$, shorter time to complete the TUG test $(10.5 \pm 4.8$ vs. $11.9 \pm 4.3 \mathrm{sec}$, respectively; $\mathrm{p}=0.001$ ), higher BBS scores (better balance; 51.5 \pm 5.8 vs. 50.5 \pm 6.1 , respectively; $\mathrm{p}=0.001)$ and similar HADS scores (Table 2). 


\begin{tabular}{|c|c|c|c|c|c|c|}
\hline \multicolumn{7}{|c|}{$\begin{array}{c}\text { TABLE } 2 \\
\text { Clinical and biopsychological findings in patients with neck pain according to presence and etiology dizziness }\end{array}$} \\
\hline & \multicolumn{3}{|c|}{$\begin{array}{c}\text { Dizziness } \\
\end{array}$} & \multicolumn{3}{|c|}{ Etiology of dizziness $(\mathrm{n}=947)$} \\
\hline & Present $(n=947)$ & Absent $(n=122)$ & $p$ & MPS $(n=565)$ & Other $(n=382)$ & $p$ \\
\hline Sternocleidomastoid muscle trigger point (MPS)§ & & & $0.001^{1}$ & & & - \\
\hline Right & $84(8.9)$ & $6(4.9)$ & & - & - & \\
\hline Left & $163(17.2)$ & $13(10.7)$ & & - & - & \\
\hline Bilateral & $173(18.3)$ & $11(9.0)$ & & - & - & \\
\hline None & $527(55.6)$ & $92(75.4)$ & & - & - & \\
\hline Trapezius muscle trigger point (MPS)§ & & & $0.267^{1}$ & & & - \\
\hline Right & $119(12.6)$ & $17(13.9)$ & & - & - & \\
\hline Left & $165(17.4)$ & $19(15.6)$ & & - & - & \\
\hline Bilateral & $568(60.0)$ & $67(54.9)$ & & - & - & \\
\hline None & $95(10.0)$ & $19(15.6)$ & & - & - & \\
\hline Dizziness handicap Inventory (DHI) & $\begin{array}{l}35.3 \pm 20.5 \\
32(0-100)\end{array}$ & - & - & $\begin{array}{c}33.7 \pm 20.2 \\
30(0-98)\end{array}$ & $\begin{array}{c}37.6 \pm 20.8 \\
36(0-100)\end{array}$ & $0.004^{2}$ \\
\hline Timed Up-and-Go (TUG) test (sec) & $\begin{array}{l}11.1 \pm 4.7 \\
10(3-92)\end{array}$ & $\begin{array}{l}7.7 \pm 3.8 \\
7(3-25)\end{array}$ & $0.001^{2}$ & $\begin{array}{l}10.5 \pm 4.8 \\
10(3-92)\end{array}$ & $\begin{array}{c}11.9 \pm 4.3 \\
11(3-49.5)\end{array}$ & $0.001^{2}$ \\
\hline Berg Balance Scale (BBS) & $\begin{array}{c}51.1 \pm 6.0 \\
53(0-64)\end{array}$ & $\begin{array}{c}55.6 \pm 1.5 \\
56(48-56)\end{array}$ & $0.001^{3}$ & $\begin{array}{c}51.5 \pm 5.8 \\
53(15-56)\end{array}$ & $\begin{array}{l}50.5 \pm 6.1 \\
52(0-64)\end{array}$ & $0.001^{3}$ \\
\hline HADS-anxiety $(\mathrm{n}=944)$ & $\begin{array}{c}8.21 \pm 5.27 \\
7(0-36)\end{array}$ & $\begin{array}{c}7.75 \pm 5.27 \\
8(0-21)\end{array}$ & $0.363^{2}$ & $\begin{array}{l}8.3 \pm 5.4 \\
8(0-33)\end{array}$ & $\begin{array}{l}8.0 \pm 5.0 \\
7(0-36)\end{array}$ & $0.377^{2}$ \\
\hline HADS-depression $(\mathrm{n}=944)$ & $\begin{array}{c}8.57 \pm 6.12 \\
7(0-34)\end{array}$ & $\begin{array}{c}6.77 \pm 5.84 \\
6(0-37)\end{array}$ & 0.0022 & $\begin{array}{c}8.40 \pm 6.23 \\
7(0-33)\end{array}$ & $\begin{array}{c}8.82 \pm 5.96 \\
8(0-34)\end{array}$ & $0.340^{2}$ \\
\hline
\end{tabular}

\begin{tabular}{|c|c|c|c|c|}
\hline \multicolumn{5}{|c|}{$\begin{array}{c}\text { TABLE } 3 \\
\text { Features of dizziness }(\mathrm{n}=947)\end{array}$} \\
\hline & Total $(\mathrm{n}=947)$ & MPS ( $\mathrm{n}=565)$ & $\begin{array}{l}\text { Etiology of dizziness } \\
\text { Other }(\mathrm{n}=382)\end{array}$ & $p^{1}$ \\
\hline Duration (month) & $\begin{array}{l}24.7 \pm 35.2 \\
12(1-240)\end{array}$ & $\begin{array}{l}23.2 \pm 34.4 \\
12(1-240)\end{array}$ & $\begin{array}{l}26.9 \pm 36.4 \\
12(1-240)\end{array}$ & $0.047^{2}$ \\
\hline Course (min) & $\begin{array}{c}7.9 \pm 69.8 \\
0.33(0.02-1440)\end{array}$ & $\begin{array}{c}7.7 \pm 65.4 \\
0.3(0-1440)\end{array}$ & $\begin{array}{c}8.3 \pm 75.9 \\
0.5(0-1440)\end{array}$ & $0.437^{2}$ \\
\hline \multicolumn{5}{|l|}{ NDS scores } \\
\hline Severity & $\begin{array}{l}4.4 \pm 2.0 \\
4(0-10)\end{array}$ & $\begin{array}{l}4.3 \pm 2.0 \\
4(0-10)\end{array}$ & $\begin{array}{c}4.6 \pm 2.0 \\
4(0-9)\end{array}$ & $\mathbf{0 . 0 3 4 ^ { 2 }}$ \\
\hline Impact on QoL & $\begin{array}{l}3.7 \pm 2.2 \\
3(0-10)\end{array}$ & $\begin{array}{l}3.6 \pm 2.1 \\
3(0-10)\end{array}$ & $\begin{array}{l}4.0 \pm 2.2 \\
4(0-10)\end{array}$ & $0.005^{2}$ \\
\hline Presence of motion sickness $\S$ & $222(23.4)$ & $131(23.2)$ & $91(23.8)$ & 0.821 \\
\hline Concomitant nausea $\$$ & $242(25.6)$ & $128(22.7)$ & $114(29.8)$ & 0.040 \\
\hline Concomitant vomiting $\$$ & $56(5.9)$ & $39(6.9)$ & $17(4.5)$ & 0.117 \\
\hline \multicolumn{5}{|l|}{ Triggering or aggravating factors ${ }^{*} \S$} \\
\hline None & $124(13.1)$ & $76(13.5)$ & $48(12.6)$ & 0.692 \\
\hline Head movement (rotation, backward) & $310(32.7)$ & $175(31.0)$ & $135(35.3)$ & 0.160 \\
\hline Migraine & $99(10.5)$ & $59(10.4)$ & $40(10.5)$ & 0.989 \\
\hline Standing up quickly & $580(61.2)$ & $351(62.1)$ & $229(59.9)$ & 0.500 \\
\hline Body movement & $756(79.8)$ & $448(79.3)$ & $308(80.6)$ & 0.615 \\
\hline Stress & $640(67.6)$ & $366(64.8)$ & $274(71.7)$ & 0.025 \\
\hline Other & $73(7.7)$ & $42(7.4)$ & $31(8.1)$ & 0.700 \\
\hline
\end{tabular}




\section{Dizziness characteristics}

In patients with dizziness ( $\mathrm{n}=947)$, the median duration of dizziness was 12 (range, 1 to 240) months, with a median of $0.33 \mathrm{~min}$ duration of a vertigo attack. Continuous and intermittent type of dizziness was noted in 29 (3.1\%) and 918 (96.9\%) patients. The median NDS scores on severity and QoL were 4 (range, 0 to 10 ) and 3 (range, 0 to 10 ), respectively (Table 3 ).

The patients with dizziness due to MPS versus other reasons had lesser duration of dizziness (23.2 $\pm 34.4 v s$. $26.9 \pm 36.4$ months, respectively; $\mathrm{p}=0.047)$ and lower NDS scores for dizziness severity $(4.3 \pm 2.0$ vs. $4.6 \pm 2.0$, respectively; $\mathrm{p}=0.034)$ and impact on QoL (3.6 \pm 2.1 vs. $4.0 \pm 2.2$, respectively; $\mathrm{p}=0.005)$, lower rates of nausea (22.7 vs. $29.8 \%$, respectively; $\mathrm{p}=0.040$ ) and a lower likelihood of aggravation of dizziness by stress (64.8 vs. $71.1 \%$, respectively; $\mathrm{p}=0.025$ ) (Table 3 ).

Numeric Dizziness Scale dizziness severity scores

The NDS dizziness severity scores were positively correlated with age $(\mathrm{r}=0.115, \mathrm{p}=0.001)$, duration of vertigo $(\mathrm{r}=0.102, \mathrm{p}=0.002)$, course of an attack $(r=0.324, p=0.001)$, DHI scores $(r=0.408, p=0.001)$ and HADS-A $(r=0.199, p=0.001)$ and HADS-D $(r=0.170$, $\mathrm{p}=0.001)$ scores, while they were negatively correlated with the BBS scores $(\mathrm{r}=-0.171, \mathrm{p}=0.001)$ (Table 4).

Logistic regression analysis revealed that female versus male sex (odds ratio [OR: 1.641, 95\% CI: 1.241 to $2.171, \mathrm{p}=0.001$ ), housewifery versus other occupations (OR: $1.285,95 \%$ CI: 1.006 to $1.642, \mathrm{p}=0.045$ ) and literacy without education (OR: 2.410, 95\% CI: 1.587 to $3.661, \mathrm{p}<0.001)$, primary education (OR: $2.564,95 \%$

\begin{tabular}{|c|c|c|c|c|}
\hline \multicolumn{5}{|c|}{$\begin{array}{c}\text { TABLE } 4 \\
\text { Numeric Dizziness Scale dizziness severity scores acc }\end{array}$} \\
\hline & \multicolumn{4}{|c|}{ NDS dizziness severity scores } \\
\hline & Mean \pm SD & Median & Min-Max & $p$ \\
\hline \multicolumn{4}{|l|}{ Sex } & \multirow[t]{3}{*}{$0.026^{1}$} \\
\hline Female & $4.48 \pm 1.96$ & 4 & $0-10$ & \\
\hline Male & $4.07 \pm 2.05$ & 4 & $0-10$ & \\
\hline \multicolumn{4}{|l|}{ Occupation } & \multirow[t]{8}{*}{$0.229^{2}$} \\
\hline Desk job & $4.08 \pm 1.74$ & 4 & $1-9$ & \\
\hline Long hours with the same neck position & $4.49 \pm 2.17$ & 4 & $1-10$ & \\
\hline Housewife & $4.52 \pm 1.95$ & 4 & $0-10$ & \\
\hline Retired & $4.13 \pm 1.89$ & 4 & $0-8$ & \\
\hline Employee & $4.18 \pm 2.07$ & 4 & $0-10$ & \\
\hline Officer & $4.90 \pm 2.24$ & 4 & $1-10$ & \\
\hline Student & $3.83 \pm 2.14$ & 4 & $1-6$ & \\
\hline \multicolumn{4}{|l|}{ Educational status } & \multirow[t]{6}{*}{$0.020^{2}$} \\
\hline Literate, not educated & $4.83 \pm 1.98^{*}$ & 5 & $1-10$ & \\
\hline Primary school & $4.53 \pm 1.92$ & 4 & $0-10$ & \\
\hline Secondary school & $4.19 \pm 2.00$ & 4 & $0-10$ & \\
\hline \multirow[t]{3}{*}{ Higher education } & $4.29 \pm 2.04$ & 4 & $1-10$ & \\
\hline & \multicolumn{3}{|c|}{ NDS dizziness severity scores ${ }^{3}$} & \\
\hline & \multicolumn{2}{|c|}{$\mathrm{r}$} & \multicolumn{2}{|l|}{$p^{3}$} \\
\hline Age (year) & \multicolumn{2}{|c|}{0.115} & \multicolumn{2}{|c|}{0.001} \\
\hline Duration of dizziness & \multicolumn{2}{|c|}{0.102} & \multicolumn{2}{|c|}{0.002} \\
\hline Cause of an attack (min) & \multicolumn{2}{|c|}{0.324} & \multicolumn{2}{|c|}{0.001} \\
\hline Dizziness Handicap Inventory (DHI) & \multicolumn{2}{|c|}{0.408} & \multicolumn{2}{|c|}{0.001} \\
\hline Berg Balance Scale (BBS) & \multicolumn{2}{|c|}{-0.171} & \multicolumn{2}{|c|}{0.001} \\
\hline HADS-anxiety & \multicolumn{2}{|c|}{0.199} & \multicolumn{2}{|c|}{0.001} \\
\hline HADS-depression & \multicolumn{2}{|c|}{0.170} & \multicolumn{2}{|c|}{0.001} \\
\hline
\end{tabular}




\begin{tabular}{|c|c|c|c|c|}
\hline \multicolumn{5}{|c|}{$\begin{array}{l}\text { TABLE } 5 \\
\text { Logistic regression analysis for factors associated with the inc } \\
\text { patients with neck pain }(n=2,361)\end{array}$} \\
\hline & \multirow[b]{2}{*}{ OR } & \multicolumn{2}{|c|}{$\% 95 \mathrm{CI}$} & \multirow[b]{2}{*}{$p$} \\
\hline & & Lower bound & Upper bound & \\
\hline Sex (female $v s$. male) & 1.641 & 1.241 & 2.171 & 0.001 \\
\hline Educational status ( $v s$. higher education) & 2.410 & 1.587 & 3.661 & $<0.001$ \\
\hline Literacy, no education & 2.564 & 1.926 & 3.413 & $<0.001$ \\
\hline Primary education & 1.649 & 1.242 & 2.188 & 0.001 \\
\hline Secondary education & 1.285 & 1.006 & 1.642 & 0.045 \\
\hline Occupational status (housewifery $v s$. others) & 1.285 & 1.006 & 1.642 & 0.045 \\
\hline
\end{tabular}

CI: 1.926 to $3.413, \mathrm{p}<0.001)$ and secondary education (OR: $1.649,95 \%$ CI: 1.242 to $2.188, \mathrm{p}=0.001$ ) versus higher education were associated with a significantly increased risk of dizziness in patients with neck pain (Table 5).

\section{DISCUSSION}

Our findings revealed the presence of concomitant cervicogenic dizziness in $40 \%$ of neck pain patients and indicated MPS as the most common etiology for both neck pain and concomitant cervicogenic dizziness. The presence versus absence of dizziness was associated with poorer functional mobility, poorer balance and a depressive state, while the increase in dizziness severity was associated with higher dizzinessrelated handicap and poorer balance.

Similarly, previous studies revealed the presence of concomitant dizziness in $35 \%$ patients with neck pain, ${ }^{[25]}$ as well as more severe disability and increased pain intensity in chronic cervical pain patients with versus without concomitant dizziness. ${ }^{[26]}$ Posturographic studies also revealed abnormal static and dynamic balance parameters in chronic neck pain patients suffering from dizziness, along with a correlation between functional complaints and posturographic parameters. ${ }^{[25,27,28]}$ Dizziness symptoms have also been associated with impaired cervical proprioception secondary to neck pain, ${ }^{[25]}$ while the severity of vertigo symptoms was reported to be correlated with the degree of vertigo-related handicap. ${ }^{[29-31]}$

Association of higher HADS scores with the increased dizziness severity in our cohort support the consideration of psychological distress related to anxiety and depression to be a relevant mediator between dizziness symptoms and dizziness-related handicap. ${ }^{[29,31-33]}$ This emphasizes the role of routine psychological assessment in patients with dizziness in terms of the potential role of treating psychological distress in limiting the effect of the dizziness symptoms on handicap. ${ }^{[29]}$

According to our findings, the factors increasing the likelihood of dizziness (female sex, older age, lower educational level and longer symptom duration) seem also to decrease the likelihood of MPS-related dizziness or to increase severity of dizziness. Besides, the presence of MPS seems also to be associated with a less severe dizziness with lesser impact on QoL, lesser disability, better functional mobility and better balance status. This seems to emphasize that not all patients suffering from dizziness symptoms develop handicap. Better clinical course seems likely in males, in those with MPS etiology, younger age and higher education in terms of severity of dizziness, handicap due to dizziness and balance problems. Given the likelihood of underlying etiology and certain biopsychosocial factors to be involved in the presence and worsening of vertigo in chronic neck patients, our findings indicate the importance of screening for dizziness, particularly in patients at a higher risk for increased dizziness-related handicap. Our findings also support the episodic nature (lasting minutes to hours) and typical symptoms (cervical pain, vertigo or dizziness, imbalance) of cervicogenic dizziness, as considered to fit the definition of imbalance rather than an illusory perception of rotational or linear movement. ${ }^{[6,9-12]}$ Additionally, the mean DHI scores in our patients with dizziness are consistent with the association of cervicogenic dizziness with mild disability and better clinical course than vestibular pathologies. ${ }^{[34-36]}$

Identification of MPS that originates from trigger points as the most common etiology for the neck pain 
and to be frequently accompanied with cervicogenic dizziness in our cohort seem to support a neck-related cause for certain episodes of dizziness owing to the principal role of the cervical spine in maintenance of posture. ${ }^{[25]}$ This seems also notable given the consideration of MPS as the most frequent, but at the same time the most often under-diagnosed or misdiagnosed pain condition, despite the availability of effective therapeutic interventions for MPS when properly identified. ${ }^{[37]}$

In a previous study among 72 patients with cervicogenic dizziness, MPS in the face, neck and shoulders was reported in $97 \%$ of patients along with improvement in dizziness symptoms via treatment for MPS in $70 \%$ patients. $^{[13]}$ The authors also noted a significant difference in the distribution of trigger points between cervicogenic dizziness patients and MPS patients without dizziness, with a higher rate of trigger points in the lateral neck muscles and involvement of sternocleidomastoid muscle only among cervicogenic dizziness patients. In addition, they indicated similarly high rates for upper trapezius muscle and cervical paraspinal muscle involvement in cervicogenic dizziness patients and MPS patients without dizziness. This seems to be consistent with the identification of trigger points most commonly in the trapezius muscle in our neck patients regardless of the concomitant dizziness, whereas higher rates of bilateral sternocleidomastoid muscle trigger point in MPS among neck pain patients with versus without dizziness. Therefore, our findings support the development of dizziness via muscles that have trigger points and frequent involvement of cervical and shoulder regions, sternocleidomastoid muscle, in particular, among MPS cases with concomitant vertigo. ${ }^{[13,38,39]}$

Notably, an outpatient rehabilitation program focusing on cervical pain in patients with chronic cervical MPS and concurrent dizziness was reported to be associated with an average Visual Analog Scale (VAS) improvement in dizziness, pain and function in $59 \%, 69 \%$ and $71 \%$ of patients, respectively with no further episodes of dizziness in $27 \%$ of patients. ${ }^{[40]}$

In a study among 32 patients with MPS involving trigger points at the clavicular division of the sternocleidomastoid muscle and concomitant non-rotatory vertigo, 10 sessions of superficial heat application and stretching on the sternocleidomastoid muscle was reported to be associated with complete disappearance of dizziness complaints in 13 patients, while complaints were decreased by $50 \%$ in 19 patients. ${ }^{[39]}$ Thus, our findings support that assessment for MPS should be integrated into the routine physical examination of the neck pain patients, ${ }^{[39]}$ as a common and treatable etiology underlying both neck pain and concomitant dizziness.

The major strength of this study seems to be inclusion of the representative sample of neck pain patients as recruited from 19 centers across Turkey increasing the likelihood of generalizability of our findings. However, certain limitations to this study should be considered. First, data on clinical and biopsychological tests were available in relatively small number of patients without cervicogenic dizziness, which otherwise would extend the knowledge achieved in the current study. Second, while patients from different PMR centers across Turkey were involved, the potential impact of geographic differences on dizziness symptoms was not analyzed. Third, the majority of the study population consisted of females, while this is consistent with the demographic characteristics in real-life clinical practice across PMR outpatient clinics in our country. Indeed, the predominance of females among the outpatients admitting with neck pain and myofascial pain syndrome has been reported previously in studies from Turkey ${ }^{[41,42]}$ Nevertheless, despite these certain limitations, given the paucity of the solid information available on this area, our findings represent a valuable contribution to the literature.

In conclusion, our findings suggest the presence of cervicogenic dizziness in nearly half of neck pain patients with a significant impact of certain biopsychosocial factors on the likelihood (female sex, housewifery, and lower educational level) and severity (underlying etiology, older age, female sex, educational level, higher psychological distress) of concomitant dizziness. In addition, MPS was the most common etiology for both neck pain and frequently accompanied with dizziness, while it was associated with better clinical status in terms of dizziness severity, dizziness-related handicap, functional mobility, and balance status. Accordingly, our findings emphasize the importance of screening for concomitant dizziness in routine investigation of neck pain patients and screening for MPS and psychological distress in those with dizziness, in terms of potential benefit from targeted therapeutic interventions to improve dizziness symptoms. There is a need for long-term follow-up studies addressing the potential risk factors for vertigo in neck pain patients, as well as the relationship between MPS and cervicogenic dizziness. 


\section{Declaration of conflicting interests}

The authors declared no conflicts of interest with respect to the authorship and/or publication of this article.

\section{Funding}

The authors received no financial support for the research and/or authorship of this article.

\section{REFERENCES}

1. Binder AI. Cervical spondylosis and neck pain. BMJ 2007;334:527-31.

2. Li Y, Peng B. Pathogenesis, diagnosis, and treatment of cervical vertigo. Pain Physician 2015;18:E583-95.

3. Neuhauser HK, Radtke A, von Brevern M, Lezius F, Feldmann M, Lempert T. Burden of dizziness and vertigo in the community. Arch Intern Med 2008;168:2118-24.

4. Hain TC. Cervicogenic causes of vertigo. Curr Opin Neurol 2015;28:69-73.

5. Yang L, Chen J, Yang C, Pang X, Li D, Wu B, et al. Cervical intervertebral disc degeneration contributes to dizziness: A clinical and immunohistochemical study. World Neurosurg 2018;119:e686-e693.

6. Sung YH. Upper cervical spine dysfunction and dizziness. J Exerc Rehabil 2020;16:385-91.

7. Michels T, Lehmann N, Moebus S. Cervical vertigo-cervical pain: An alternative and efficient treatment. J Altern Complement Med 2007;13:513-8.

8. Peng B. Cervical vertigo: Historical reviews and advances. World Neurosurg 2018;109:347-50.

9. Wrisley DM, Sparto PJ, Whitney SL, Furman JM. Cervicogenic dizziness: a review of diagnosis and treatment. J Orthop Sports Phys Ther 2000;30:755-66.

10. Hahn T, Halatsch ME, Wirtz C, Klessinger S. Response to cervical medial branch blocks in patients with cervicogenic vertigo. Pain Physician 2018;21:285-94.

11. Yacovino DA, Hain TC. Clinical characteristics of cervicogenic-related dizziness and vertigo. Semin Neurol 2013;33:244-55.

12. L'Heureux-Lebeau B, Godbout A, Berbiche D, Saliba I. Evaluation of paraclinical tests in the diagnosis of cervicogenic dizziness. Otol Neurotol 2014;35:1858-65.

13. Cho DK, Rhee CK, Lee SJ, Jang YY, Hyun JK. Myofascial pain syndrome in patients with cervical vertigo. J Korean Acad Rehab Med 2011;35:243-9.

14. Barry E, Galvin R, Keogh C, Horgan F, Fahey T. Is the Timed Up and Go test a useful predictor of risk of falls in community dwelling older adults: A systematic review and meta-analysis. BMC Geriatr 2014;14:14.

15. Podsiadlo D, Richardson S. The timed "Up \& Go": A test of basic functional mobility for frail elderly persons. J Am Geriatr Soc 1991;39:142-8.

16. Jacobson GP, Newman CW. The development of the Dizziness Handicap Inventory. Arch Otolaryngol Head Neck Surg 1990;116:424-7.

17. Brown KE, Whitney SL, Marchetti GF, Wrisley DM, Furman JM. Physical therapy for central vestibular dysfunction. Arch Phys Med Rehabil 2006;87:76-81.
18. Ellialtıoğlu A, Karan A, Erdamar B, Aksoy S. Selim paroksismal pozisyonel vertigo tanılı hastalarda partikülü yeniden yerleştirici manevraya habitüasyon egzersizi ilave etmenin tedavi etkinliği ve yaşam kalitesi üzerine etkileri. Türkiye Fiziksel Tıp ve Rehabilitasyon Dergisi 2003;49:36-41.

19. Berg K, Wood-Dauphine S, Williams JI, Gayton D. Measuring balance in the elderly: Preliminary development of an instrument. Physiotherapy Canada 1989;41:304-11.

20. Berg KO, Maki BE, Williams JI, Holliday PJ, WoodDauphinee SL. Clinical and laboratory measures of postural balance in an elderly population. Arch Phys Med Rehabil 1992;73:1073-80.

21. Sahin F, Büyükavcı R, Sağ S, Doğu B, Kuran B. Berg denge ölçeği'nin Türkçe versiyonunun inmeli hastalarda geçerlilik ve güvenilirliği. Türk Fiz Tip Rehab Derg 2013;59:170-5.

22. Zigmond AS, Snaith RP. The hospital anxiety and depression scale. Acta Psychiatr Scand 1983;67:361-70.

23. Andersson, E. The hospital anxiety and depression scale. Homogeneity of the subscales. Social Behavior and Personality: An international journal 1993;21:197-204.

24. Aydemir O. Validity and reliability of Turkish version of Hospital Anxiety and Depression Scale. Turkish Journal of Psychiatry 1997;8:280-7.

25. Yahia A, Ghroubi S, Jribi S, Mâlla J, Baklouti S, Ghorbel A, et al. Chronic neck pain and vertigo: Is a true balance disorder present? Ann Phys Rehabil Med 2009;52:556-67.

26. Humphreys BK, Peterson C. Comparison of outcomes in neck pain patients with and without dizziness undergoing chiropractic treatment: A prospective cohort study with 6 month follow-up. Chiropr Man Therap 2013;21:3.

27. Alund M, Ledin T, Odkvist L, Larsson SE. Dynamic posturography among patients with common neck disorders. A study of 15 cases with suspected cervical vertigo. J Vestib Res 1993;3:383-9.

28. Faux P, Manas-Gomez F, Petit H. Posturome'trie et cervicalgie chronique. Ann Readapt Med Phys 1997;40:450-1.

29. Probst T, Dinkel A, Schmid-Mühlbauer G, Radziej K, Limburg K, Pieh C, et al. Psychological distress longitudinally mediates the effect of vertigo symptoms on vertigo-related handicap. J Psychosom Res 2017;93:62-8.

30. Tschan R, Wiltink J, Best C, Beutel M, Dieterich M, EckhardtHenn A. Validation of the German version of the Vertigo Handicap Questionnaire (VHQ) in patients with vestibular vertigo syndromes or somatoform vertigo and dizziness. Psychother Psychosom Med Psychol 2010;60:e1-12.

31. Yardley L, Masson E, Verschuur C, Haacke N, Luxon L. Symptoms, anxiety and handicap in dizzy patients: Development of the vertigo symptom scale. J Psychosom Res 1992;36:731-41.

32. Eckhardt-Henn A, Breuer P, Thomalske C, Hoffmann SO, Hopf HC. Anxiety disorders and other psychiatric subgroups in patients complaining of dizziness. J Anxiety Disord 2003;17:369-88.

33. Lee H, Hübscher M, Moseley GL, Kamper SJ, Traeger AC, Mansell G, et al. How does pain lead to disability? A systematic review and meta-analysis of mediation studies in people with back and neck pain. Pain 2015;156:988-97.

34. Grande-Alonso M, Moral Saiz B, Mínguez Zuazo A, Lerma Lara S, La Touche R. Biobehavioural analysis of 
the vestibular system and posture control in patients with cervicogenic dizziness. A cross-sectional study. Neurologia (Engl Ed) 2018;33:98-106.

35. Kristjansson E, Treleaven J. Sensorimotor function and dizziness in neck pain: Implications for assessment and management. J Orthop Sports Phys Ther 2009;39:364-77.

36. Reiley AS, Vickory FM, Funderburg SE, Cesario RA, Clendaniel RA. How to diagnose cervicogenic dizziness. Arch Physiother 2017;7:12.

37. Giamberardino MA, Affaitati G, Fabrizio A, Costantini R. Myofascial pain syndromes and their evaluation. Best Pract Res Clin Rheumatol 2011;25:185-98.

38. Cummings M, Baldry P. Regional myofascial pain: Diagnosis and management. Best Pract Res Clin Rheumatol 2007;21:367-87.
39. Karan A, Diraçoğlu D, Erdamar B, Ellialtıŏlu A, Uluğ T, Aksoy C. A Neglected reason of vertigo and a new approach to the patient with vertigo: Myofascial pain syndrome. Nobel Med 2008;4:17-21.

40. Krabak BJ, Borg-Stein J, Oas JA. Chronic cervical myofascial pain syndrome: Improvement in dizziness and pain with a multidisciplinary rehabilitation program. A pilot study. J Back Musculoskelet Rehabil 2000;15:83-7.

41. Ay S, Konak HE, Evcik D, Kibar S. The effectiveness of Kinesio Taping on pain and disability in cervical myofascial pain syndrome. Rev Bras Reumatol Engl Ed 2017;57:93-9.

42. Sahin N, Karataş O, Ozkaya M, Cakmak A, Berker E. Demographics features, clinical findings and functional status in a group of subjects with cervical myofascial pain syndrome. Agri 2008;20:14-9. 